\title{
Mesenchymal Stem Cells and/or 1-2-oxothiazolidine-4-Carboxylate Improve Hyperlipidemia and Lung Cell Proliferation in Chlorpyrifos-Treated Rats
}

\author{
Nawal S. Hassan ${ }^{1}$, Nora E.M. Shaheen ${ }^{2} \mathbb{D}$, Nawal Z. Haggag ${ }^{2} \mathbb{D}$, Marwa T. Hassen ${ }^{2, * \mathbb{D}}$
}

1 Physiology Department, Faculty of Medicine and Health Sciences, Zawia University, Libya; nawal.198040@yahoo.com (N.S.H.);

2 Zoology Department, Faculty of Women for Arts, Sciences and Education, Ain Shams University, Egypt; nora.shaheen@women.asu.edu.eg (N.E.M.S.); nawal.haggag@women.asu.edu.eg (N.Z.H.); meropinky87@gmail.com (M.T.H.);

* Correspondence: meropinky87@gmail.com (M.T.H.);

Scopus Author ID: 57202162299

Received: 8.10.2021; Revised: 5.11.2021; Accepted: 8.11.2021; Published: 28.11.2021

\begin{abstract}
This study aimed to examine the impact of 1-2-oxothiazolidine-4-carboxylate (OTC) or/and bone marrow mesenchymal stem cells (MSCs) on CPF-induced lung toxicity in rats. Male albino rats were divided into six groups. Control: received distilled water; OTC: received OTC (100 mg/kg b.wt./day, oral for one month); CPF (toxicity group) received CPF (17.5 mg/kg b.wt/day, oral for one month; CPF+OTC, $\mathrm{CPF}$ group treated with OTC; $\mathrm{CPF}+\mathrm{MSC}$, $\mathrm{CPF}$ group treated with MSCs (a single intravenous injection of $2 \times 10^{6}$ cell in PBS and left for one month) and CPF+OTC+MSCs, CPF group co-treated with OTC and MSCs. Results showed significant improvement in body weights, relative lung weights, total protein and albumin, lipid profile, and arterial blood gases $\left(\mathrm{pO}_{2}\right.$ and $\left(\mathrm{pCO}_{2}\right)$ levels in rats treated with either OTC alone or with MSCs. OTC or/and MSCs exhibited remarkable anti-inflammatory activities evident by increased interleukin-10 (IL-10) and decreased C-reactive protein (CRP), in lung tissues. Notably, OTC or/and MSCs administration exerted restorative effects on the pulmonary parenchyma structure and associated functional impairments. BM-MSCs and OTC combination has the ability to suppress the CPF-induced lung toxicity and could prove to be a novel approach to therapy for acute and chronic lung injury in rats.
\end{abstract}

Keywords: lung toxicity; hyperlipidemia; mesenchymal stem cells; chlorpyrifos; antioxidant.

(C) 2021 by the authors. This article is an open-access article distributed under the terms and conditions of the Creative Commons Attribution (CC BY) license (https://creativecommons.org/licenses/by/4.0/).

\section{Introduction}

The concept that mesenchymal stem cells (MSCs) are immature, heterogeneous, stromal populations of multipotent nonhematopoietic adult stem cells and like hematopoietic cells have been and remain is useful for the aim of tissue engineering. MSCs have proliferative potential and can give different cells, which are related to the germinal layer. A study in 1924, by Alexander A. Maximow, used detailed histological detection to classify the special form of precursor cells inside the mesenchyme that grow into different types of blood cells. Generally, MSCs are cell types with multilineage differentiation potential and self-renewal ability that remain in various tissue and organ types, including adipose tissue, bone marrow, umbilical cord, fallopian tubes, skin, peripheral blood, liver, and lung [1]. 
Recently, stem cells have generated more professional and public interest than almost any other topic in biology. Their differentiation capability has motivated clinicians and scientists to seek suitable protocols to apply these cells to manage various diseases [2]. Fortunately, regenerative medicine accommodates a potential strategy to treat a variety of degenerative illnesses [3]. For example, a 2018 study [3] showed that MSC grafts could secrete antiinflammatory factors and differentiate into lung alveolar epithelial cells, but they also deliver some vehicles for gene therapy in repairing the injured lung to prevent pulmonary fibrosis. Recently, multiple studies have shown that MSCs have the potential to treat patients who complain of degenerative diseases [4]. Subsequently, many scientists and clinicians have attempted to manage various diseases using MSCs-based therapy. However, as a novel therapy, MSCs still face various limitations [5].

Chen et al., 2020 [6] provided evidence that lung stem cells (LSCs) could facilitate the repair of lung injury by maintaining the potential of multilineage differentiation and transdifferentiating into alveolar cell type II cells next in vitro stimulation of fibroblast growth factor 10 (FGF10). In controlling lung infection and inflammation, vagal-alpha7 nicotinic acetylcholine receptor signaling plays a vital role. Vagotomy or alpha7nAChR deficiency lowers the expression of FGF10 in the lung and the count of AEC2.

In a recent study conducted by Liu et al., 2020 [7], they reported the L-2-oxothiazolidine4-carboxylate (OTC), known as procysteine. It is a white to off-white, soluble, crystalline powder with a distinctive odor of sulfur. OTC is an amino acid L-cysteine cyclic derivative compound. The free sulfur group ( $\mathrm{SH}$ ) has become a part of the ring structure through the synthesis process, offering the sulfur with beneficial added oxidative stability. In addition, this moiety has an asymmetric carbon that creates an optically active compound. Procysteine is an intracellular precursor to cysteine so that it can be converted into cysteine enzymatically. In the synthesis of glutathione, cysteine is the rate-limiting substance. In a range of health contexts, cellular glutathione levels may be important. For instance, OTC, a lipophilic cysteine precursor that is converted intracellularly to free cysteine through the oxo-L-prolinase reaction, is an active thiol compound [8]. The potency of cysteine precursors and OTC supplementation at GSH levels have been assessed and used to improve GSH concentrations in animal and human models. OTC supplementation has been tested in populations with low GSH status for its effect on GSH homeostasis, comparable to other cysteine prodrugs [9].

In a recent study conducted by Ur Rahman et al., 2020 [10], they reported that the CPF is a wide-spectrum organophosphates (OPs) pesticide used in fruits, vegetables, as well as homes, and several other locations for the prevention of insects and pathogens. Neurological disorders, endocrine and cardiovascular diseases (CVDs) have been related to the toxicity of CPF. It has been established that CPF exposure is associated with developmental disorders such as attention deficit hyperactivity, autism, developmental retardation [11,12], genotoxicity, hematological malignancies, histopathological distortions, and immune toxicity and oxidative stress [13]. Moreover, due to CPF toxicity, eye inflammation and dermatological imperfections are also recognized. CPF causes neurotoxicity because it has hyperactivity in cholinergic signals in the synapse, so causes lethal overstimulation of neurotransmission [14]. It has been suggested that the CPF-toxicity to cells is related to the lipophilicity of CPF, which facilitates its penetration from the cell membrane and induces oxidative stress [15]. In addition, CPF toxic mode is linked with 
inhibition of sodium and calcium channels, Calmodulin-Calcium system, which induce inflammation, apoptosis, GABA receptors, and disruption of the cell membrane and its lipid level [16-18]. Moreover, according to Szafran et al., 2021[19], endocannabinoid (eCB) is a metabolizing enzyme and has an immune-modulatory function. $\mathrm{eCB}$ is more sensitive than $\mathrm{AChE}$ to be inhibited by $\mathrm{CPF}$, so it disorders lung $(\mathrm{eCB})$ and disrupts lung immune responses. A recent study demonstrated that exposure to $\mathrm{CPF}$, cypermethrin, or their combination cause damage in mice lungs through the dysregulation of Apaf1 gene expression [20]. While CPF substance has low perseverance in the body, its active metabolites 3,5,6-trichloro-2-pyridinol (TCP) and chlorpyrifos-oxone (CPO) are considerably more stable, albeit similarly harmful, causing significant health problems. Importantly, it was documented that the CPF effect extends to causing disturbances in lipid metabolism so, it plays a crucial role in lipid imbalance and causes hyperlipidemia and/or oxidative stress to the pathogenesis of lung diseases, including chronic obstructive pulmonary disease (COPD) [21,22].

The goal of this study was to assess the efficacy of L-2-oxothiazolidine-4-carboxylate and/or bone marrow mesenchymal stem cells (BM-MSCs) on suppressing risks related to OPD as hyperlipidemia and some biochemical disturbances. Then restoration of immunohistochemical features of cells proliferative capacity in lung toxicity induced by chlorpyrifos in rats.

\section{Materials and Methods}

\subsection{Chemicals.}

L-2-Oxothiazolidine-4-Carboxylate (98\% in purity) and chloropyrifos (97\% in purity) were purchased from Sigma Chemical Company (St. Louis, U.S.A).

\subsection{Experimental animals.}

Forty-eight adult male albino rats (weighing 120 $\pm 10 \mathrm{~g}$ ) were obtained from the animal house of the National Research Center, Cairo, Egypt. All rats were housed in metal cages at a temperature of $24-27^{\circ} \mathrm{C}, 12$ hours dark/ light cycle. All rats were fed on a standard diet for normal rats (fat $5 \%$, carbohydrates $65 \%$, proteins, $20.3 \%$ fiber $5 \%$, salt mixture, and $3.7 \%$ vitamin mixture $1 \%$ ) [23], and water was available all time throughout the experimental period. All rats were acclimatized to the new environment for 2 weeks before the onset of the experiment. All the ethical protocols for animal treatment were followed and supervised by the animal facilities, National Research Center. All animal experiments received approval from the animal care committee, National Research Center (registration number: 13/165).

\subsection{Induction of pulmonary toxicity.}

The pulmonary toxicity model was induced by chlorpyrifos administered orally to male rats $17.5 \mathrm{mg} / \mathrm{kg}$ for 30 days [24]. 


\subsection{Bone marrow mesenchymal stem cells (BM-MSCs).}

Pkh26-labeled bone marrow mesenchymal stem cells of rats were obtained from the Biochemistry and Molecular Biology Unit, Faculty of Medicine, Cairo University. Stem cells were prepared according to the literature [25-27].

\subsection{Experimental design.}

All rats were divided into two main groups:

GROUP A. (16 rats) divided into 2 groups each of 8 rats: Group I: control group received distilled water daily; Group II: received 1-2-oxothiazolidine-4-carboxylate orally (100mg/kg for one month) at the beginning of MSCs transplantation.

GROUP B. (32 rats) were divided into 4 groups after oral administration of Chlorpyrifos (17.5mg/kg for one month) [24]: Group III (CPF): remain with no further treatment; Group IV: treated with 1-2-oxothiazolidine-4-carboxylate $(100 \mathrm{mg} / \mathrm{kg}$ for one month) [28]; Group V: treated with stem cells ( with both stem cells companies with 1-2-oxothiazolidine-4-carboxylate.

After one month of MSCs administration, all experimental rats were sacrificed under ether anesthesia [29], and the lung tissue was dissected and fixed on formalin for histopathological investigation. Lung tissues were fixed in formalin in order to the immune-histological investigation. Furthermore, $1 \mathrm{gm}$ of the lung was homogenized. The homogenates were preserved at $-80^{\circ} \mathrm{C}$ before biochemical experiments were required.

\subsection{Morphological studies.}

2.6.1. Determination of total body weight, lung weight, and relative lung weight.

\subsubsection{Total body weight.}

Animals of control and treated groups were weighed prior to the time of treatment by using a sensitive electronic balance, weekly and again prior to sacrifice. The differences between the initial and final weights were calculated to determine the percentage of change in body weight within the whole period of the experiment, thus:

Percentage of change in body weight:

$$
\frac{\text { Final body weight }- \text { Initial body weihgt }}{\text { Initial body weight }} \times 1 \text { oo }
$$

\subsubsection{Lungs and relative lungs weight.}

At the time of sacrifice, rats from control and treated groups were weighed and sacrificed. The thoracic cavity was opened, and the lungs were rapidly removed, blotted with a piece of filter paper, and weighed. The lung weight was calculated relative to the total body weight, thus:

$$
\text { Relative lung weights }=\frac{\text { Lung weight }}{\text { Total body weight }} \times 100
$$




\subsection{Biochemical analysis.}

\subsubsection{Determination of protein profile.}

Total protein in serum was examined colorimetrically as described by Kholif et al., 2014 [30]. Serum albumin level was estimated colorimetrically according to Daumas et al., 1971[31].

\subsubsection{Determination of lipid profile.}

Serum cholesterol level was determined by the method of Siedel et al., 1983 [32]. The commercial kit was purchased from Randox, U.K. The determination of serum triglyceride (TG) level was determined according to Fossati and Prencipe, 1982[33]. The kit was purchased from Randox, U. K. High-density lipoprotein (HDL) level in serum was determined according to the manufacturer of by using a commercial kit purchased from Randox, U. K. The level of high-density lipoprotein (LDL) was estimated according to the following equation

$$
\mathrm{LDL}=\text { Cholesterol }-\mathrm{HDL}-(0.16) \text { Triglyceride [34]. }
$$

\subsubsection{Interleukine-10 (IL-10) measurement.}

Interleukin-10 level in serum was determined according to the method of Okura et al., 1998 [35].

\subsubsection{Determination of inflammatory markers.}

Serum CRP levels were tested by using a high-sensitivity immunoassay according to manufacturer protocols [36].

\subsubsection{Measurement of arterial blood gases.}

The arterial partial pressures of $\mathrm{O}_{2}$ and $\mathrm{CO}_{2}\left(\mathrm{pO}_{2}\right.$ and $\left.\mathrm{pCO}_{2}\right)$ were analyzed immediately in a multifunctional blood gas analyzer (Cobas b 121; Roche, Mannheim, Germany) [37].

\subsection{Immunohistochemical staining.}

Immunostaining was performed on the sections using the Avidin-Biotin-Peroxidase complex (ABC) technique. After deparaffinization by incubation at $60 \mathrm{C}^{\circ}$ for 30 minutes and dehydration in a graded ethanol series, the sections were incubated sequentially with the following solutions: (1) $0.3 \%$ hydrogen peroxide in absolute methanol for 30 minutes to remove endogenous peroxidase activity; (2) normal horse serum for 30 minutes to reduce background staining; (3) PC10 dilution of 1:100 with overnight incubation at $4 \mathrm{C}^{\mathrm{o}}$ was found to be optimal; (4) $\mathrm{ABC}$ complexes (Dakopatts) diluted 1:200 at room temperature for 40 minutes; (5) 0.03\% 3,3diaminobenzidine tetrahydrochloride solution to which hydrogen peroxide $(0.02 \%)$ was added just before use. Between each step of the immunostaining procedure, the sections were washed in phosphate-buffered saline (PBS). The presence of a brown-colored nuclei product at the target antigen site indicates positive reactivity [38]. 


\subsection{Statistical analysis}

Statistical analysis was performed by using the statistical package for social science (SPSS, Chicago, IL) version 17statistical software. All data were analyzed by one-way ANOVA analysis. Differences were considered significant at $p<0.05$. Data were expressed as the mean $\pm \mathrm{SE}$.

\section{Results and Discussion}

\subsection{Homing of MSCs.}

PKH26 labeled stem cells were detected in lung tissue after 12 days of MSCs transplantation, strong homing of labeled cells was observed in lung sections treated with mesenchymal stem cells and OTC together, Figure 1.

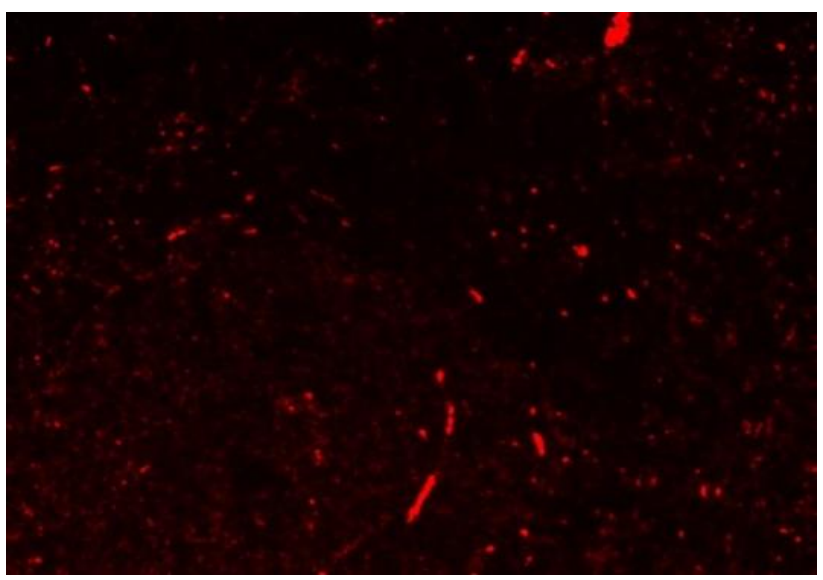

Figure 1. PKH26 labeled stem cells in lung showing stronger red fluorescence after treatment with both MSCs and 1-2-oxothiazolidine-4-carboxylate.

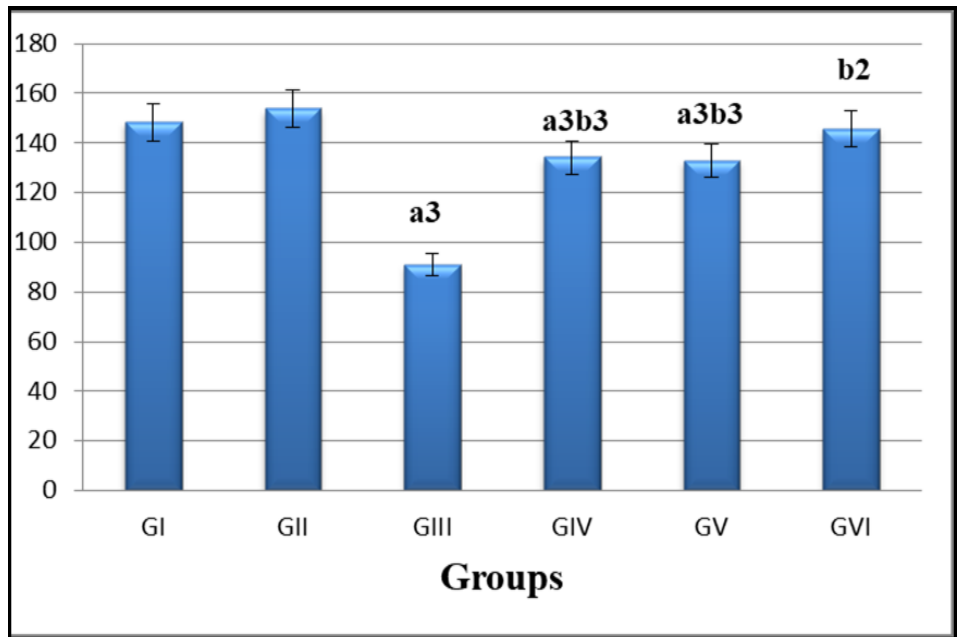

Figure 2. The therapeutic role of OTC or/and MSCs on total body weight level (g) at the end of the study of rats treated with CPF. a: Statistically significant compared to corresponding value in controls (control and OTC) groups.

b: Statistically significant compared to the corresponding value in CPF group. $1:(p<0.05), 2:(p<0.01) \& 3$ : $(p<0.001)$ GI (control group), GII (OTC group), GIII (CPF group), GIV (CPF+OTC group), GV (CPF+MSCs group), GVI (CPF+OTC+MSCs). 


\subsection{Determination of total body weight, lung weight, and relative lung weight.}

It is obvious from Figure 2 that the data relating to control rats (GI) indicated a rise in body weight. At the beginning of the experiment, the average body weight was $120 \pm 10 \mathrm{~g} / \mathrm{animal}$ and reached $(148.34 \pm 1.63 \mathrm{~g})$ at the end of the experiment.

In comparison, the mean value of body weight of CPF rats (GIII) observed $(90.88 \pm 1.32 \mathrm{~g})$ decreased significantly $(p<0.001)$ compared to the control group. Only the OTC group showed no difference compared to the control group $(p>0.05)$. Further, $\mathrm{CPF}+\mathrm{OTC}$ and $\mathrm{CPF}+\mathrm{MSC}$ groups (GIV and GV) showed a significant increase $(p<0.001)$ in total body weight, the mean values recording $(134.25 \pm 1.54 \mathrm{~g}$ and $132.74 \pm 1.69 \mathrm{~g})$, respectively as compared to the CPF group. Also, the mean values of body weight recorded a significant increase $(P<0.001)$ in the $\mathrm{CPF}+\mathrm{MSC}+\mathrm{OTC}$ group $(145.60 \pm 0.97 \mathrm{~g})$ when compared to CPF rats $(90.88 \pm 1.32 \mathrm{~g})$.

The data represented in Figure 3 revealed a significant increase $(p<0.001)$ in total lung weight of CPF group (GIII) recorded a change (173.77\%) as compared to the control group. In contrast, no significant changes $(p>0.05)$ in the total lung weight of OTC group (GII) compared to the control $(\mathrm{GI})$. A significant decrease $(p<0.001)$ occurred in the mean lung weight in both, $\mathrm{CPF}+\mathrm{OTC}$ group (GIV) and $\mathrm{CPF}+\mathrm{MSCs}$ group $(\mathrm{GV})$ as compared to $\mathrm{CPF}$ group. The percentage of the mean lung weight reached $(1.13 \pm 0.04 \mathrm{~g}$ and $0.84 \pm 0.03 \mathrm{~g})$, respectively. Furthermore, the average lung weights of the $\mathrm{CPF}+\mathrm{OTC}+\mathrm{MSC}$ group $(\mathrm{GVI})$ recorded a significant $(p<0.001)$ decrease and reached $(-59.28 \%)$ compared to $\mathrm{CPF}$ group. But, a non-significant increase $(p>0.05)$ occurred in the mean lungs weight in both the $\mathrm{CPF}+\mathrm{MSC}$ group $(\mathrm{GV})$ and $\mathrm{CPF}+\mathrm{OTC}+\mathrm{MSCs}$ rats (GVI) as compared to the control group. The percentage reached $(37.71 \%$ and $11.48 \%$ ), respectively.

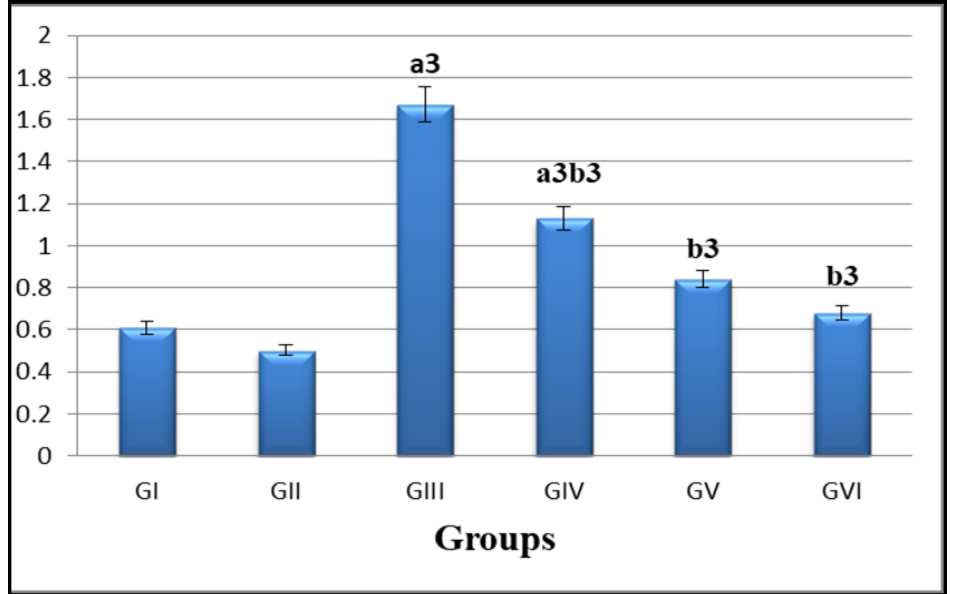

Figure 3. The therapeutic role of OTC or/and MSCs on total Lungs weight (g) of rats treated with CPF. a:

Statistically significant compared to corresponding value in controls (control and OTC) groups. b: Statistically significant compared to the corresponding value in CPF group. 1:(p<0.05), 2: $(p<0.01) \& 3:(p<0.001)$ GI (control group), GII (OTC group), GIII (CPF group), GIV (CPF+OTC group), GV (CPF+MSCs group), GVI

(CPF+OTC+MSCs).

Figure 4 indicates the average lung weight to body weight ratio for each group. No significant differences were found in the relative weight of lungs and body weight in the OTC (GII) group compared to control rats (GI). The percentages of change for (GV and GVI) in relation to the control group no significant increase $(P>0.05)$, where the percent of change for these groups 
were $(64.29 \%$ and $17.86 \%)$, respectively as compared to control rats. While the percentages of change for CPF administered group (GIII) were (432.14\%) as compared to the control. In contrast, the relative lung weight was decreased in (GVI) recorded (-77.85\%) as compared with CPF group. Whereas the percentage of change for (GIV) in relation to control rats showed a significant increase $(P<0.001)$, where the percent of change for this group was $(128.57 \%)$.

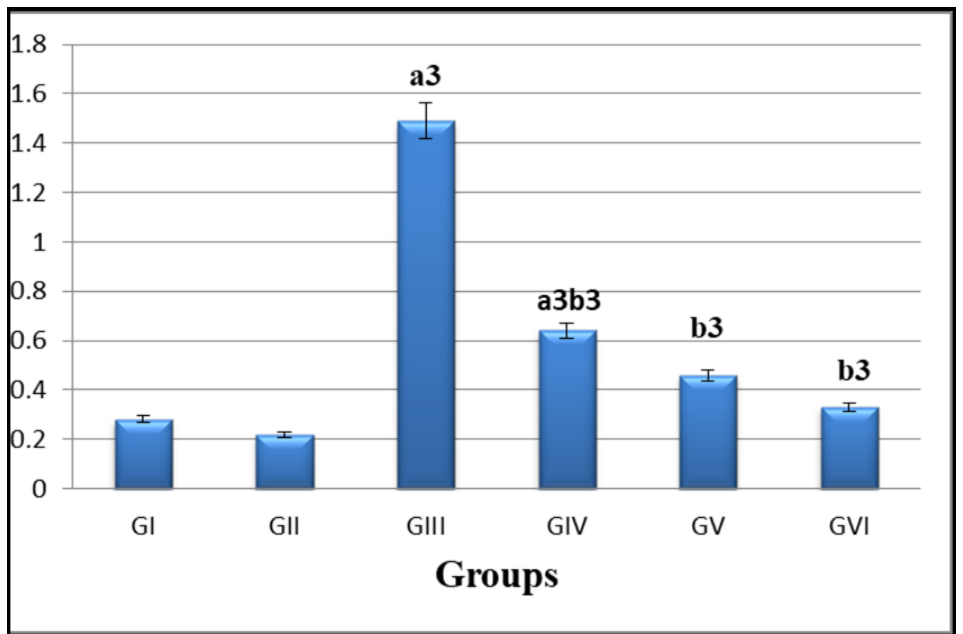

Figure 4. The therapeutic role of OTC or/and MSCs on relative lungs weight (\%) of rats treated with CPF. a:

Statistically significant compared to corresponding value in controls (control and OTC) groups. b: Statistically significant compared to the corresponding value in CPF group. 1:( $p<0.05), 2:(p<0.01) \& 3:(p<0.001)$ GI (control group), GII (OTC group), GIII (CPF group), GIV (CPF+OTC group), GV (CPF+MSCs group), GVI

(CPF+OTC+MSCs).

\subsection{Biochemical analysis.}

\subsubsection{Protein profile.}

The recorded values of tissue total protein and tissue albumin were presented in Figure 5 and Figure 6.

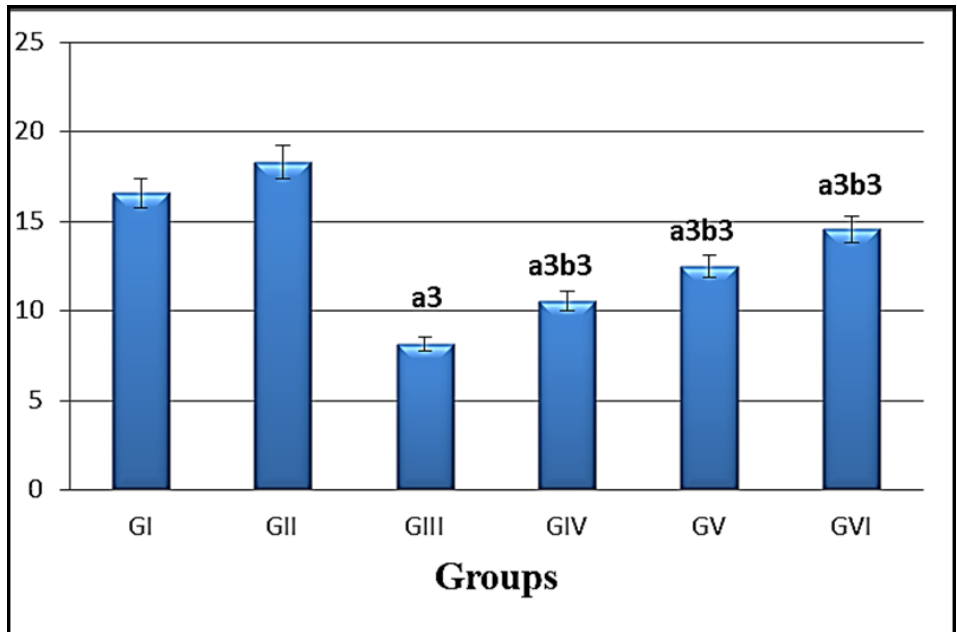

Figure 5. The therapeutic role of OTC or/and MSCs on tissue T-Protein $(\mathrm{g} / \mathrm{mg})$ of rats treated with CPF. a:

Statistically significant compared to corresponding value in controls (control and OTC) groups. b: Statistically significant compared to the corresponding value in CPF group. 1: $(p<0.05), 2:(p<0.01) \& 3:(p<0.001)$ GI (control group), GII (OTC group), GIII (CPF group), GIV (CPF+OTC group), GV (CPF+MSCs group), GVI

(CPF+OTC+MSCs). 
The total tissue protein in CPF rats (GIII) was significantly decreased $(P<0.001)$ compared to the control group reaching $(-50.85 \%)$, while, for OTC group (GII), total protein was reached to normal with a change of $(10.64 \%)$, from control and (125.09\%) from CPF group. In addition, the total tissue protein in the $\mathrm{CPF}+\mathrm{OTC}$ group (GIV) and CPF+MSCs group (GV) recorded a significant elevation $(P<0.001)$ compared to the CPF rats. The percentages of change were (29.64\%) for (GIV) and (53.51\%) for (GV) from the CPF administered group. In contrast, partial recovery took place in the $\mathrm{CPF}+\mathrm{OTC}+\mathrm{MSCs}(\mathrm{GVI})$. The percentage of their increase reached (78.84\%) in total protein as compared to CPF group. This means that, compared to other groups, the treated group with OTC showed a significant improvement in the level of total tissue protein.

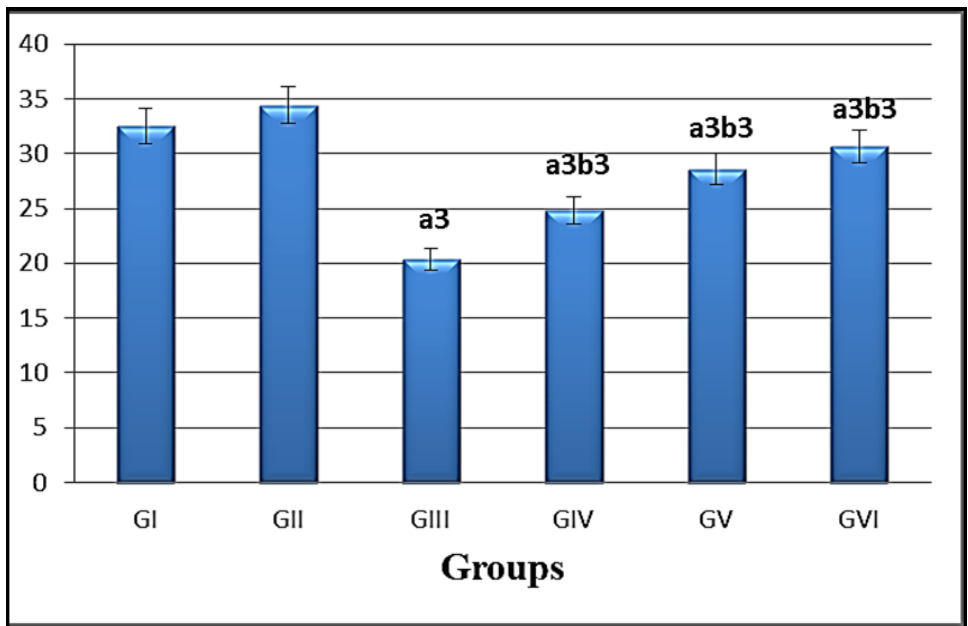

Figure 6. The therapeutic role of OTC or/and MSCs on tissue albumin (g/mg) of rats treated with CPF. a:

Statistically significant compared to corresponding value in controls (control and OTC) groups. b: Statistically significant compared to the corresponding value in CPF group. 1: $(p<0.05), 2:(p<0.01) \& 3:(p<0.001) \mathrm{GI}$ (control group), GII (OTC group), GIII (CPF group), GIV (CPF+OTC group), GV (CPF+MSCs group), GVI

(CPF+OTC+MSCs).

Partial changes were recorded in the OTC rats (GII) with percent of changes $(6.04 \%)$ in total albumin when compared to the control group, while the CPF rats (GIII) showed a significant decrease $(p<0.001)$ reaching $(-37.22 \%)$ in relation to the control rats. Furthermore, partial recovery occurred in the $\mathrm{CPF}+\mathrm{OTC}$ group (GIV) and $\mathrm{CPF}+\mathrm{MSC}$ rats $(\mathrm{GV})$. The percentage of their decline reached $(-23.69 \%)$ and $(-12.02 \%)$, respectively, in total albumin compared to the control group. In relation to the control group (GI) a significant increase $(p<0.001)$ in total albumin was reported in (GVI) reaching $(-5.58 \%)$.

\subsubsection{Lipid profile.}

The mean values of control and experimental groups' serum total cholesterol, TG, HDL, and LDL levels are presented in Figures 7, 8, 9, and 10. No remarkable changes were noted in the level of serum total cholesterol of OTC rats (GII) compared with control. The total cholesterol level was increased significantly $(p<0.001)$ to $(98.67 \pm 3.27 \mathrm{mg} / \mathrm{dl})$ for CPF rats group (GIII) compared to the control group $(50.26 \pm 2.45 \mathrm{mg} / \mathrm{dl})$, with a percent of change $(96.32 \%)$. Also, a significant increase $(p<0.001)$ was observed in the CPF+MSCs rats $(\mathrm{GV})$ as compared to control, with an average value of $(71.80 \pm 2.38 \mathrm{mg} / \mathrm{dl})$ and percentage of change $(42.86 \%)$ from control. Whereas, therapeutic with $\mathrm{CPF}+\mathrm{OTC}$ (GIV) induced a significant increase $(P<0.05)$ in total 
cholesterol level $(61.18 \pm 2.13 \mathrm{mg} / \mathrm{dl})$ in comparison with the control group. While in the $\mathrm{CPF}+\mathrm{OTC}+\mathrm{MSC}$ group (GVI), total cholesterol levels were nearly similar to that in the control group and reached $(56.63 \pm 2.73 \mathrm{mg} / \mathrm{dl})$. The percentages of change were $(12.67 \%)$ as shown in Figure 7.

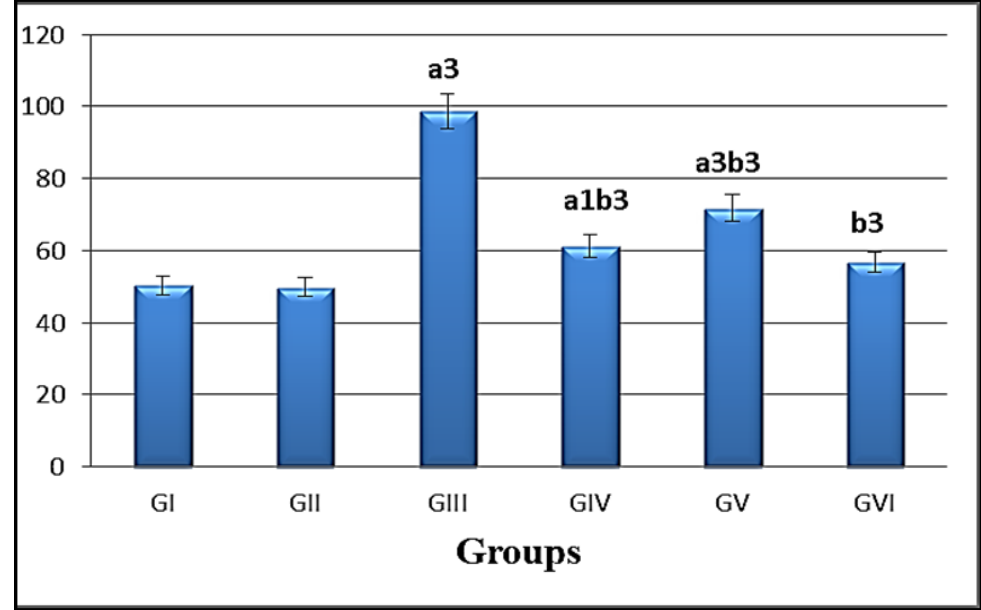

Figure 7. The therapeutic role of OTC or/and MSCs on serum cholesterol level (mg/dl) of rats treated with CPF. a: Statistically significant compared to corresponding value in controls (control and OTC) groups. b: Statistically significant compared to the corresponding value in CPF group. 1: $(p<0.05), 2:(p<0.01) \& 3:(p<0.001) \mathrm{GI}$ (control group), GII (OTC group), GIII (CPF group), GIV (CPF+OTC group), GV (CPF+MSCs group), GVI (CPF+OTC+MSCs).

The inspection of the data presented in Figure 8 showed partial changes with percent of change (-10.04\%) in the TG level of OTC group (GII) compared to control rats. On the other hand, in CPF rats group (GIII), a significant elevation $(p<0.001)$ was realized in TG level as compared with control rats (GI).

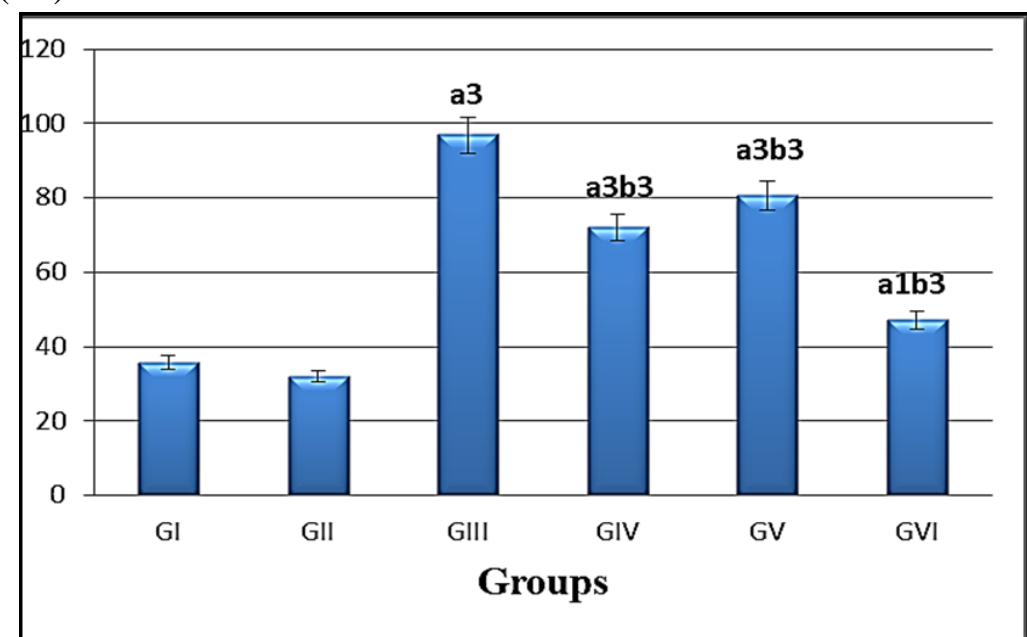

Figure 8. The therapeutic role of OTC or/and MSCs on serum TG level (mg/dl) of rats treated with CPF. a: Statistically significant compared to corresponding value in controls (control and OTC) groups. b: Statistically significant compared to the corresponding value in CPF group. 1: $(p<0.05), 2:(p<0.01) \& 3:(p<0.001)$ GI (control group), GII (OTC group), GIII (CPF group), GIV (CPF+OTC group), GV (CPF+MSCs group), GVI

$(\mathrm{CPF}+\mathrm{OTC}+\mathrm{MSCs})$.

The percentage elevation was (171.73\%) from the control group. A partial improvement was observed in TG level in CPF+OTC group (GIV) and the group treated with MSCs (GV). This improvement recording $(71.96 \pm 2.37 \mathrm{mg} / \mathrm{dl})$ and $(80.58 \pm 2.02 \mathrm{mg} / \mathrm{dl})$ as compared to CPF group 
$(96.87 \pm 3.05 \mathrm{mg} / \mathrm{dl})$, with a percent of change (101.85\%) and $(126.03 \%)$ from control and ($25.72 \%)$ and $(-16.82 \%)$ from CPF group, respectively.

Furthermore, therapeutic groups by OTC+MSCs (GVI) showed a significant partial increase in TG level as compared to the control group $(p<0.05)$, and reached $(47.19 \pm 2.55 \mathrm{mg} / \mathrm{dl})$, with a percent of change (32.37\%) from control and (-51.29\%) from CPF group Figure 10.

The results obtained in Figure 11 showed that HDL content was significantly decreased $(p<0.001)$ in the CPF group (GIII) recording $(15.35 \pm 1.43)$ compared to the control rats $(31.61 \pm 1.50 \mathrm{mg} / \mathrm{dl})$. While, no significant changes $(p>0.05)$ were found in OTC group (GII) recording $(34.61 \pm 1.70 \mathrm{mg} / \mathrm{dl})$, with a percent of change $(9.49 \%)$ from the control group (GI). On the other hand, HDL contents were significantly increased to $(24.84 \pm 1.32)(p<0.001)$ and $(22.98 \pm 1.46)(p<0.01)$ in $(\mathrm{GIV})$ and $(\mathrm{GV})$ as compared to CPF group (GIII). Moreover, a significant increase $(p<0.001)$ in $\mathrm{HDL}$ in $\mathrm{CPF}+\mathrm{OTC}+\mathrm{MSC}$ group $(\mathrm{GVI})$ as compared to $\mathrm{CPF}$ group, and reached $(28.52 \pm 1.53 \mathrm{mg} / \mathrm{dl})$, with a percent of change $(-9.78 \%)$ from control and $(85.80 \%)$ from CPF group in Figure 9.

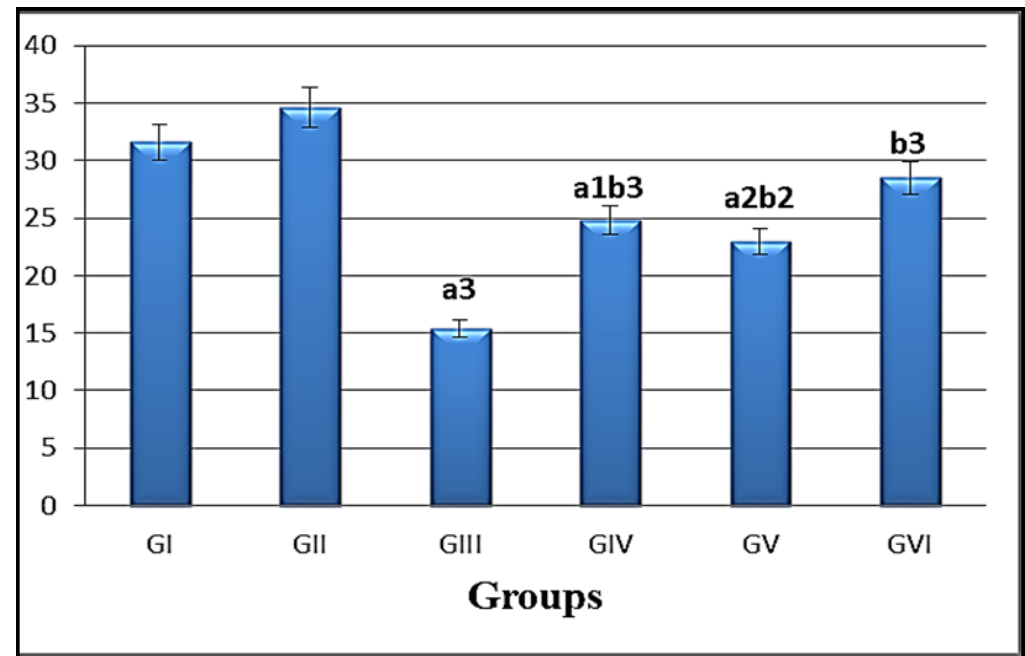

Figure 9. The therapeutic role of OTC or/and MSCs on serum HDL level (mg/dl) of rats treated with CPF. a:

Statistically significant compared to corresponding value in controls (control and OTC) groups. b: Statistically significant compared to the corresponding value in CPF group. 1:(p<0.05), 2: $(\mathrm{p}<0.01) \& 3:(\mathrm{p}<0.001)$ GI (control group), GII (OTC group), GIII (CPF group), GIV (CPF+OTC group), GV (CPF+MSCs group), GVI $(\mathrm{CPF}+\mathrm{OTC}+\mathrm{MSCs})$.

The values of LDL in the control and experimental groups are presented in Figure 10. The data showed, no remarkable changes were noted in the level of serum LDL of the OTC rats group (GII) as compared to control rats (GI), while in CPF rats (GIII) a significant percentage elevation $(p<0.001)$ of $(30.47 \%)$ in the level of LDL was recorded as compared to the control group (GI). Moreover, other groups except for the CPF+MSCs group (GV) showed no statistical difference $(p>0.05)$ in relation to the control group. The change percentages were $(8.08 \%$ and $4.25 \%)$ in (GIV and GVI), respectively, from the control group. It is clear from the data recorded that the best improvement occurred in the therapeutic rat group with OTC. In CPF+MSCs rats (GV), LDL level revealed a significant increase $(p<0.05)$ compared to the control group and recorded a change of $(20.99 \%)$ in Figure10. 


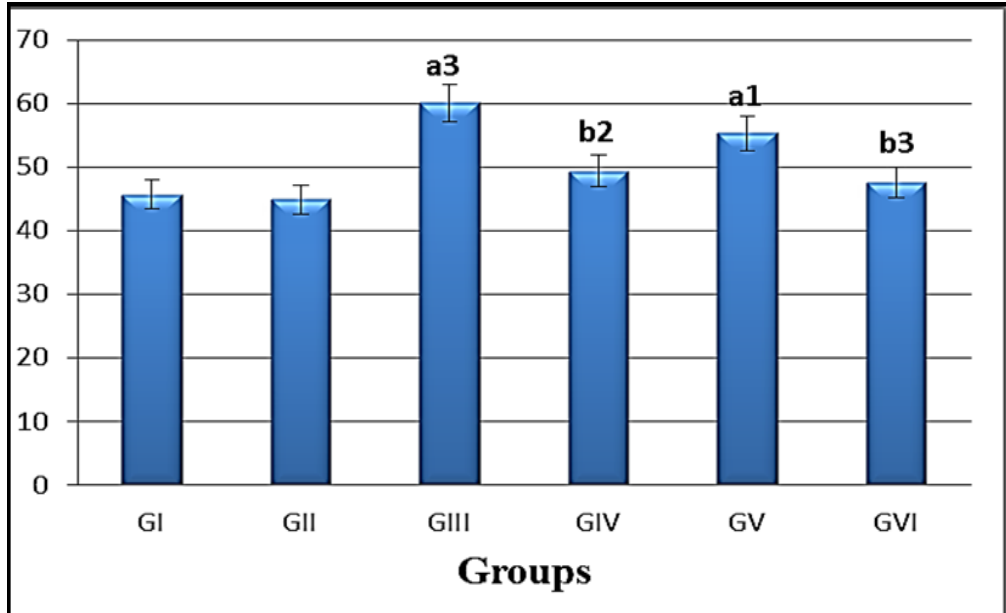

Figure 10. The therapeutic role of OTC or/and MSCs on serum LDL level (mg/dl) of rats treated with CPF. a: Statistically significant compared to corresponding value in controls (control and OTC) groups. b: Statistically significant compared to the corresponding value in CPF group. 1: $(p<0.05), 2:(p<0.01) \& 3:(p<0.001) \mathrm{GI}$ (control group), GII (OTC group), GIII (CPF group), GIV (CPF+OTC group), GV (CPF+MSCs group), GVI (CPF+OTC+MSCs).

\subsubsection{Interleukin-10 (IL-10).}

Data recorded for the values of tissue anti-inflammatory cytokine IL-10 were presented in Figure 11. The results showed insignificant changes $(p>0.05)$ with a percent of changes $(1.15 \%)$ in the tissue IL-10 of OTC group (GII) when compared to the control group.

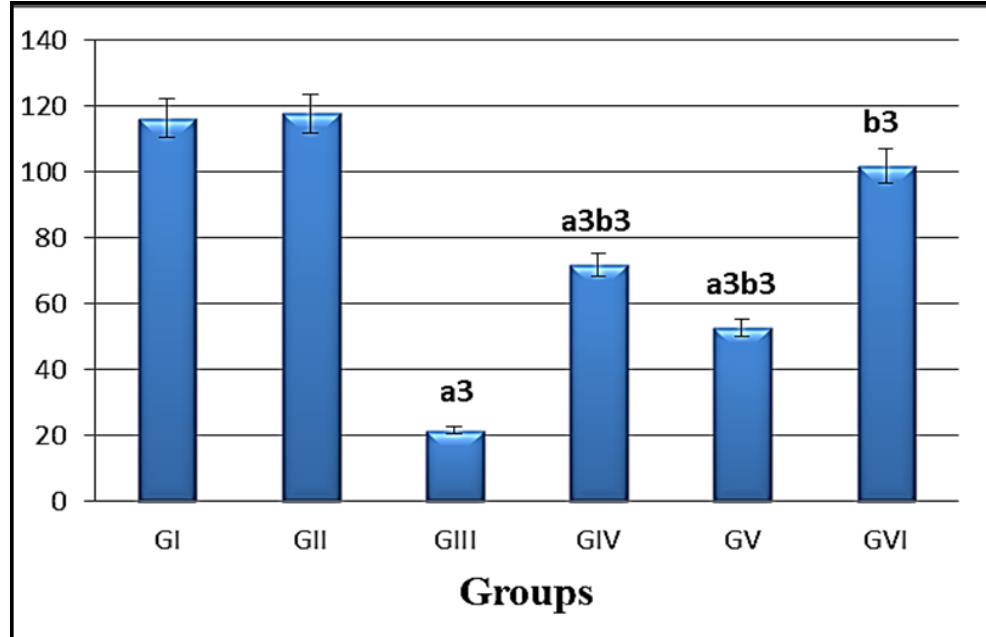

Figure 11. The therapeutic role of OTC or/and MSCs on tissue IL-10 values (pg/mg) of rats treated with CPF. a:

Statistically significant compared to corresponding value in controls (control and OTC) groups. b: Statistically significant compared to the corresponding value in CPF group. 1: $(p<0.05), 2:(p<0.01) \& 3:(p<0.001)$. GI (control group), GII (OTC group), GIII (CPF group), GIV (CPF+OTC group), GV (CPF+MSCs group), GVI (CPF+OTC+MSCs).

By another way, the data indicated a significant decrease $(p<0.001)$ in the antiinflammatory cytokine IL-10 in the group administered CPF (GIII) compared to control rats, where the average value of IL-10 was $(21.32 \pm 2.50 \mathrm{pg} / \mathrm{mg})$, with a percent of change $(-81.66 \%)$ from the control rats $(116.24 \pm 3.33 \mathrm{pg} / \mathrm{mg})$. While partial recovery occurred in the $\mathrm{CPF}+\mathrm{OTC}$ rats 
(GIV) and CPF+MSCs group (GV) in IL-10 value, the mean values were $(71.64 \pm 3.67 \mathrm{pg} / \mathrm{mg}$ and $52.73 \pm 1.91 \mathrm{pg} / \mathrm{mg})$, respectively, with the percentage of $(-38.37 \%$ and $-54.66 \%)$ from control rats (GI). Moreover, the CPF+OTC+MSCs group (GVI) reversed the ability of OTC and MSCs, as treatment, to raise the average IL-10 to non-significant change $(p>0.05)$ compared to the control rats group (GI), where the average value recorded $(101.63 \pm 4.57 \mathrm{pg} / \mathrm{mg})$, with the percentage of reduction $(-12.57 \%)$ as compared with the control group.

\subsubsection{C-reactive protein.}

On measuring the serum C-reactive protein (CRP) and level, the data graphically represented in Figure 12 were obtained. The present results revealed that the serum CRP level recorded a significant increase $(p<0.001)$ in the CPF group (GIII) was found to be $(173.31 \pm 1.80)$ as compared to control (71.14 \pm 3.00$)$, with a percent of change (143.62\%). In contrast, the group of OTC (GII) showed no difference compared to the control $(P>0.05)$. The level of CRP revealed a significant partial increase $(p<0.05)$ in the therapeutic group with OTC+MSC (GVI) compared to control groups, with an average value of $(82.1 \pm 2.03)$ and percent of change $(15.41 \%)$.

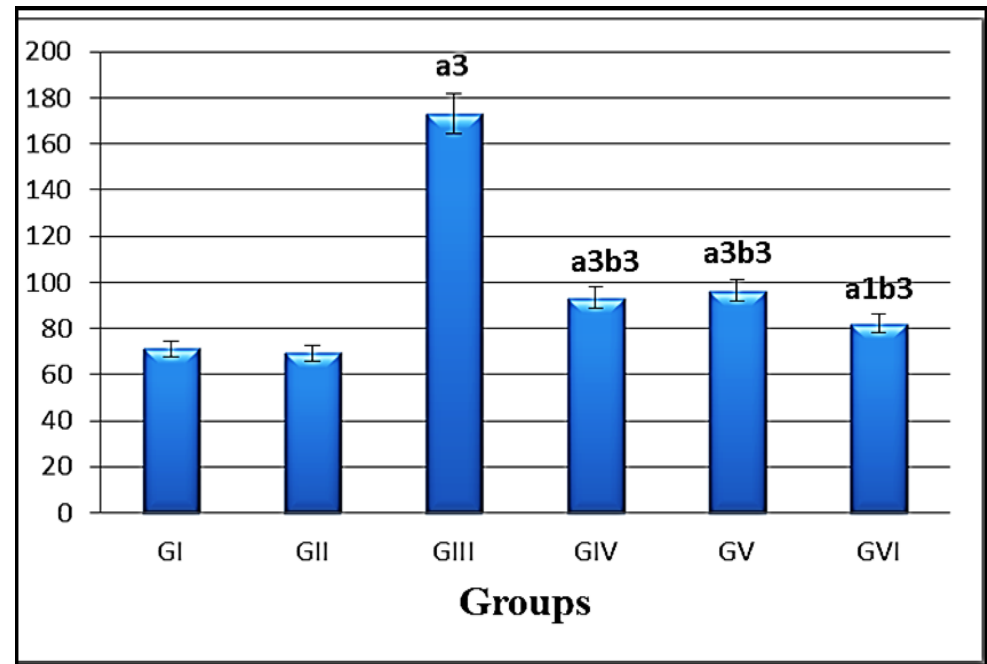

Figure 12. The therapeutic role of OTC or/and MSCs on serum CRP level $(\mu \mathrm{g} / \mathrm{ml})$ of rats treated with CPF. a: Statistically significant compared to corresponding value in controls (control and OTC) groups. b: Statistically significant compared to the corresponding value in CPF group. 1: $(p<0.05), 2:(p<0.01) \& 3:(p<0.001) \mathrm{GI}$ (control group), GII (OTC group), GIII (CPF group), GIV (CPF+OTC group), GV (CPF+MSCs group), GVI $(\mathrm{CPF}+\mathrm{OTC}+\mathrm{MSCs})$.

Furthermore, the therapeutic groups by both OTC (GIV) and MSCs (GV) showed a statistical decrease $(p<0.001)$ as compared to CPF group. The percentage of change for (GIV) in relation to control groups decreased than that of $(\mathrm{GV})$, where the percent of change for $(\mathrm{GIV})$ were (23.77\%) compared to control, while the percentage of change for (GV) were (26.23\%) compared to control group.

\subsubsection{Arterial blood gases.}

Data recorded for partial pressure of oxygen (pO2) and partial pressure of carbon dioxide (pCO2) are presented in Figures $13 \& 14$. The results in Figure 13 recorded a significant $(p<0.001)$ 
decrease in pO2 value of CPF rats (GIII) reached (-28.89\%) in comparison with the control group (GI). Moreover, no remarkable changes $(P>0.05)$ were reported in the OTC group (GII), were recorded $(0.90 \%)$ in relation to the control group. In the therapeutic rats treated with OTC + MSCs (GVI), the value was nearly returned to the control and reached $(-0.69 \%)$. whereas, the pO2 values showed partial improvement $(p<0.001)$ in (GIV and GV), which recorded $(-12.39 \%$ and $-15.61 \%)$, respectively, as compared to the control group.

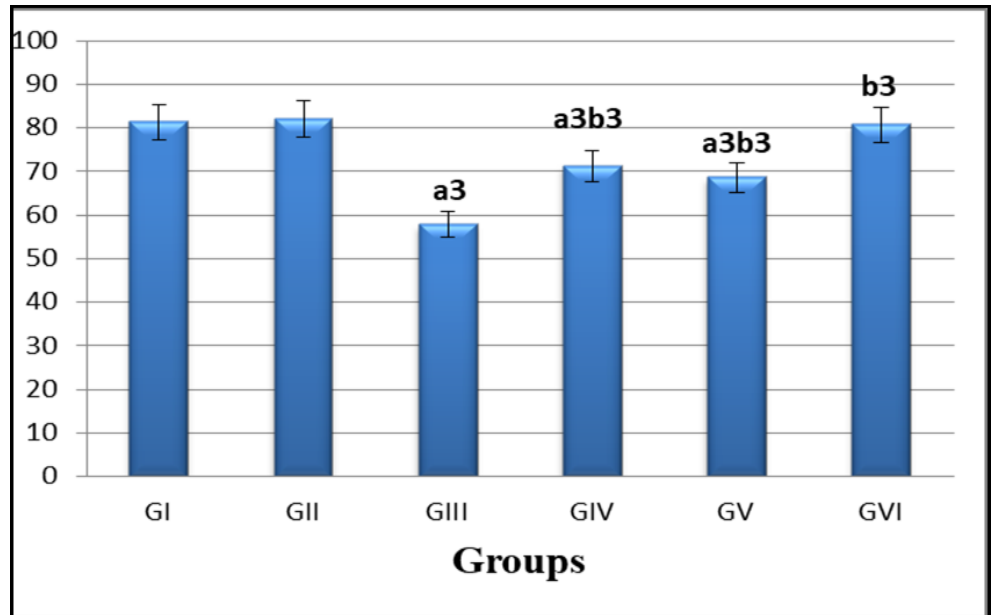

Figure 13. The therapeutic role of OTC or/and MSCs on blood pO2 level (mmHg) of rats treated with CPF. a: Statistically significant compared to corresponding value in controls (control and OTC) groups. b: Statistically significant compared to the corresponding value in CPF group. 1:(p<0.05), 2: $(p<0.01) \& 3:(p<0.001) \mathrm{GI}$ (control group), GII (OTC group), GIII (CPF group), GIV (CPF+OTC group), GV (CPF+MSCs group), GVI $(\mathrm{CPF}+\mathrm{OTC}+\mathrm{MSCs})$.

From the inspection of the data presented in Figure 14, the pCO2 level of CPF rats (GIII) showed significant elevation $(P<0.001)$, reaching $70.30 \%$ compared with the control group.

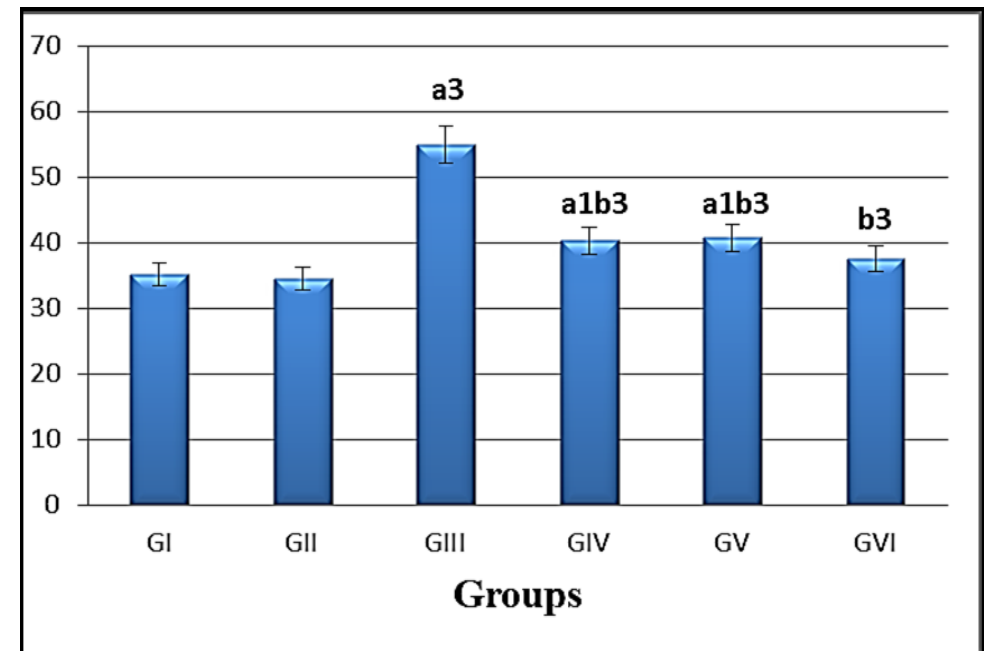

Figure 14. The therapeutic role of OTC or/and MSCs on blood pCO2 level (mmHg) of rats treated with CPF. a: Statistically significant compared to corresponding value in controls (control and OTC) groups. b: Statistically significant compared to the corresponding value in CPF group. 1:(p<0.05), 2: $(p<0.01) \& 3:(p<0.001) \mathrm{GI}$ (control group), GII (OTC group), GIII (CPF group), GIV (CPF+OTC group), GV (CPF+MSCs group), GVI

(CPF+OTC+MSCs). 
Moreover, no remarkable changes $(p>0.05)$ were reported in the OTC group (GII) as compared with the control group (GI). On the other hand, the $\mathrm{pCO} 2$ value of the therapeutic group by OTC (GIV) and therapeutic rats by MSCs $(\mathrm{GV})$ revealed minimal improvement $(p<0.05)$, as compared to the control group, with a percent of change (14.35\%) for (GIV) and (15.75\%) for (GV) compared to the control group. The therapeutic group by OTC + MSCs (GVI) induced a significant improvement $(p<0.001)$ of blood $\mathrm{pCO} 2$ value reaching $(6.82 \%)$ in comparison to control and $(-31.56 \%)$ in comparison to CPF group.

\subsubsection{Immune-histochemical studies.}

The immune histochemical examination of the lung tissue as well as the total count of pulmonary cells, which expressed positively immune reactivate of PCNA of different groups, were represented in Figure 15.

Immune-staining for PCNA was expressed as brown color fine dots. In the control (GI) and OTC (GII) groups, the lung tissues showed low expression of PCNA positive immune reactivity where nuclei appeared brownish in color (Figure $15(\mathrm{a} \& \mathrm{~b})$, while, in the CPF rats (GIII), the PCNA immune reactive cells of lung tissue showed low numbers of PCNA positive nuclei, Figure 15 (c). Groups of toxic rats treated with mesenchymal stem cells and/or OTC showed more expression and widespread of PCNA positive nuclei than CPF non-treated rats, Figure 15 (d,e \& f).
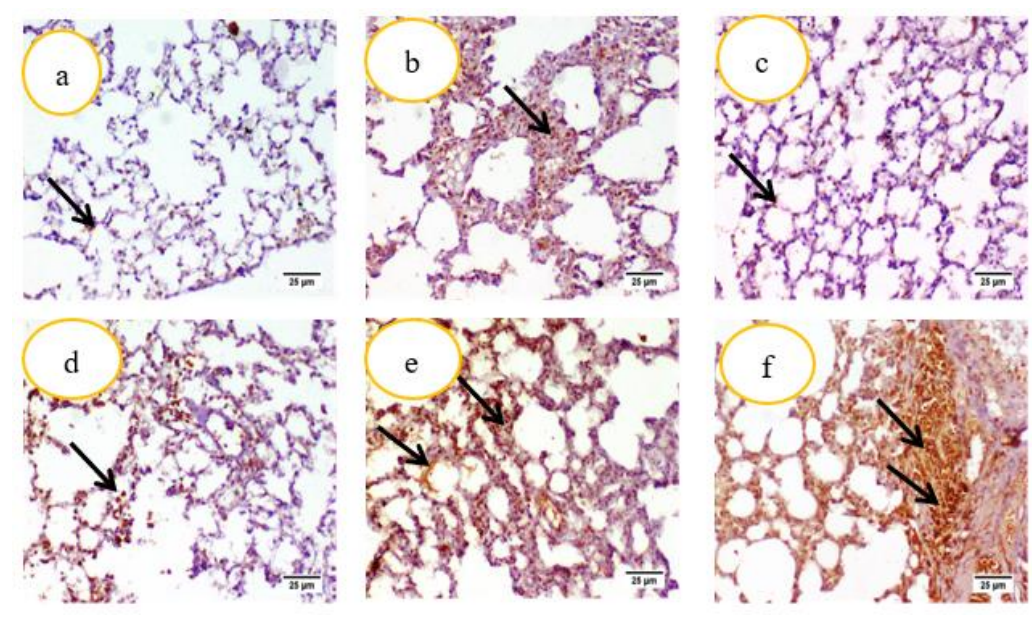

Figure 15. (a) Lung sections of a control rat showing limited normal expression of PCNA positive cells in the interalveolar wall (arrow); (b) Lung of rat, OTC group showing limited PCNA expression in some interstitial tissue cells (arrow); (c) Lung of rat, CPF group showing low peri-bronchiolar PCNA expression (arrow); (d) Lungs of rat, CPF + OTC group showing mild PCNA expression in the interstitial tissue (arrow); (e) Lungs of rat, CPF+ MSCs group showing more PCNA expression (arrow); (f) Lungs of rat, CPF+ OTC+ MSCs group showing extensive expression of PCNA in the inter-alveolar wall (arrow).

Lung toxicity, pulmonary dysfunction, and abnormal lung development may be produced as results of direct (inhalation) or indirect (oral) pesticide exposure [39,40]. Chlorpyrifos (CPF) is an organophosphates insecticide that suppresses acetylcholinesterase and affects behavioral, physiological, oxidative, histopathological, and other effects. CPF may cause toxicity by inducing oxidative stress, resulting in free radicals, changes in antioxidant properties, and lipid peroxidation [41,42]. 
The current study showed that there was a significant decrease in the total body weight, increased lungs weight, and relative lungs weight. In contrast, [43]Wang et al., 2021 reported a decrease in total body weight after treatment with CPF. Such results were markedly noticed in rats treated with CPF only (GIII) as compared to control (GI). This decrease in body weight with CPF is probably attributed to decreased feed and water intake as a result of hepatic, renal toxicity and/or as a result of significant injury to the liver tissue; metabolic activities are disrupted. This suggestion is in accordance with $[44,45]$. In this study, CPF caused a significant increase in lung weight and relative lung weight, which might be due to inflammatory infiltration and pulmonary edema. This is in accordance with [46], who mentioned that the pulmonary weight of rats treated with CPF insecticide increased in proportion to the incidences of histopathologic findings and the maximum grades of all inflammatory lesions, alveolar macrophage grades, or perivascular inflammation. Rats treated with mesenchymal stem cells (MSCs) were shown to reduce the body weight loss of lungs caused by CPF. Whereas both lungs and relative lungs weights manifested a significant decrease in those treated with MSCs. This improvement in both body and lung weights after treatment with MSCs is attributed to their ability to migrate to damaged lungs to further differentiate and develop into alveolar epithelial cells and facilitate the retention of the cells in the injured lung [10,47,48]. Furthermore, regulating gene expression in MSCs used in implantation therapy for acute lung injury can inhibit cell apoptosis, oxidative stress, and inflammatory response and promote MSCs migration and differentiation into Type II pneumocytes in injured lung tissues. So, MSCs may enhance MSCs-mediated lung tissue protection. This reality may be confirmed in the current results by more proliferative cells expressed by PCNA immune-reactivity investigations after MSCs treatment, Figure 15(e).

The present work revealed that the administration of CPF (GIII) resulted in a significant decrease in total protein and albumin compared to control rats. On the other hand, [49] reported an increase in total protein in male rats treated with CPF. The effects in tissue proteins might be explained by undernutrition and a reduction in protein synthesis in the liver on the one hand and an increase of injured and apoptotic action in lung cells on the other hand [50]. While OTC in rats administered CPF followed by OTC (GIV, GV, and GVI) revealed significant improvement in protein profile which reverse OTC role against cell injury caused by CPF. This may be due to the antioxidant capacity of OTC via restoration of normal GSH content because OTC is converted intracellular to cysteine, it might provide a more consistent source of cysteine for GSH synthesis than cysteine itself [51]. Moreover, the current study showed that MSCs-treated rats (GV and GVI) had higher albumin and total protein than CPF group, MSCs caused maintaining the protein content towards control, and this might be due to the ability of MSCs to suppress CPF-induced cell injury. These effects may be attributable, at least in part, to stem cells' capacity to repair and produce pulmonary cells as well as hepatocytes [52,53].

Hyperlipidemia is a critical risk for chronic obstructive pulmonary disease (COPD) [22,54]. High levels of serum cholesterol contribute to impaired pulmonary surfactant function. Since cholesterol is incorporated into surfactant within the alveolar type II cells, which derives its cholesterol from serum [54], disturbances in Cholesterol, TG, and LDL levels may be useful markers in the evaluation of stable COPD [21].

In the current results, the CPF group (GIII) showed significant elevation of serum cholesterol, TG, and LDL and significant reduction of HDL compared to controls. The observed 
hyperlipidemia might be related to a decrease in food and energy ingestion as a result of CPF toxicity; this prompts the body to release energy from adipose tissue to compensate for these deficits, resulting in an increase in lipid levels. These results agree with [55,56], who found hyperlipidemia with increased serum triglyceride and cholesterol after CPF-treatment, and it may be a result of the pesticide causing damaged liver cells [57]. A significant restoration in serum cholesterol, TG, HDL, and LDL levels were recorded in CPF+OTC+MSCs-treated group (VI). The hypolipidemia effect of MSCs may be related to a direct effect on the liver by inhibiting the SREBP-1 transcription factor which is responsible for lipid homeostasis [58].

Tissue IL-10 of CPF group was significantly reduced in relation to control. The high level of IL-10 indicates anti-inflammatory responses [59-61]. On the other side, OTC administrated to CPF-treated rats increased IL-10 in the lung tissue. This effect may be due to the capacity of OTC to scavenge harmful free radicals, which contribute to the inflammatory response and tissue damage that follows. The extremely poisonous hydroxyl radical $\left(\mathrm{OH}^{-}\right)$, peroxynitrite anion (ONOO-), and hypochlorous acid $(\mathrm{HOCl})$ are among the reactive oxygen and nitrogen species known to be scavenged by OTC [61,62].

The present study demonstrated that IL-10 increased in CPF-treated lungs after MSCs injection than those treated with OTC. This result suggested that MSCs has an immune-modulatory effect. Supporting this view, $[63,64]$ discussed that MScs' therapeutic potential is due to their unique characteristics, including homing to injured tissues, suppressing immunological and inflammatory responses at the target locations, and promoting tissue repair (see figure 1 in results). Additionally, according to Lou et al., 2021 [64] MSCs may regulate the immune activity via the enhancement effect for T-reg. cell activation while the inhibitory effect on $\mathrm{T}$ cell differentiation and dendritic cell proliferation. Subsequently, these facts may further explain the improvement in nuclear cell proliferation in lung tissues, represented by PCNA expressions in our study. No remarkable changes were reported in common systemic inflammatory marker C-reactive protein (CRP) level after treatment with $\mathrm{CPF}+\mathrm{OTC} \mathrm{G}$ (IV) and CPF+MSCs G (V). Furthermore, this action was shown greatly in $\mathrm{CPF}+\mathrm{OTC}+\mathrm{MSCs} \mathrm{G}$ (VI). However, this may be related to the antioxidant effects of OTC and the ability of MSCs to move to injured or inflamed tissues and cause improvement in inflammatory markers [65]. Furthermore, small extracellular vesicles produced from mesenchymal stromal cells (MSC-sEV) were shown to dramatically reduce inflammatory cell infiltration, cytokines, and the number of epithelial goblet cells in the lungs of mice with allergic airway inflammation [66]. This suggestion corroborates the increase of antiinflammatory cytokine, IL10 in the present results and the observations documented by [67], who found that MSCs can help mice recover from acute lung injuries by secreting lipoxin A4 (LXA4), the first anti-inflammatory and pro-resolving lipid mediator, and signaling through the G proteincoupled ALX/FPR2 receptors.

The current results showed a marked decrease in the level of blood $\mathrm{pO}_{2}$ and an increase in the levels of blood $\mathrm{pCO}_{2}$ in rats exposed to $\mathrm{CPF}$ (GIII). This hypoxia feature may be due to a number of structural lung diseases that reduce the efficiency of $\mathrm{O}_{2}$ transport, such as diffusion, restriction all across the alveolar-capillary membrane, ventilation-perfusion mismatched [67]. It was documented that organophosphate-induced pulmonary damage results in alveolar congestion, neutrophil invasion, emphysematous alterations, and cellular accumulation in vascular walls [68]. Moreover, [69] Yurumez et al., 2007 suggested that CPF exposure may induce lung injury by 
inducing disturbances in Atp5g2, Fau, Cox6a1, Fth1, Rps27, Rplp0, Tpt1, Hint1, Sftpd, and Sftpa. The administration of OTC and MSCs in the present investigation (GIV and GV) indicated significant improvement in $\mathrm{pO}_{2}$ and $\mathrm{pCO}_{2}$ levels, especially in $\mathrm{CPF}+\mathrm{OTC}+\mathrm{MSCs}$ rats (GVI) compared to CPF-treated ones (GIII). This improvement in gas exchanges is related to the played role of OTC and MSCs in stopping oxidative and inflammatory effects and the followed restoration of the alveolar wall and lung cells architectures [68]. Also, MSCs diminish their capacity to differentiate into lung cells. So, significant improvement in $\mathrm{pO} 2$ and pCO2 reverse the powerful antioxidant and anti-inflammatory capacity of OTC and or MSCs to restore alveolar cell wall function.

Regarding the immune-histochemical investigation, a cell proliferation marker, PCNA was examined. The results showed a low number of PCNA positive nuclei in lung tissue in CPF-treated rats. Such results indicated that $\mathrm{CPF}$ induced dysfunction and destruction of the lung histological structure is associated with the inhibition of tissue repair. The current study agrees with El-Kerdasy et al., 2021 and Kassab and El-Aasr, 2018 [70,71], who attributed a decrease in PCNA positive nuclei in the CPF group to the increase of reactive oxygen species production and induced oxidative damage, which arrest cell cycling and enhance apoptosis and collagen fiber deposition. Consequently, the ameliorating effect of OTC on PCNA reactivity might be due to its ability to attenuate the production of ROS [28].

In the same line [72] Niture et al., 2007 stated that O6-Methylguanine-DNA methyltransferase is a DNA repair protein that guards the cellular genome and serious oncogenic genes from the mutagenic act of endogenous and exogenous alkylating agents, substantially its repair activity levels following OTC therapy was related to OTC's anti-apoptotic function, which regulates the production of proteins involved in apoptotic pathways and can also support the protective effect and enhance normal cell cycle. Moreover, MSCs caused a significant increase in PCNA expression. These findings are in consideration with [73], who observed a significant increase in the number of pneumocyte type II cells and acinar formation were detected in certain fields. In our results, MSCs were detected in lung tissue, Figure 1. This improvement could be explained by an attempt of these cells to repair and differentiate into lung cells [74,75]. The regulation of gas exchange in the current results may confirm the cell repair and proliferation showed by PCNA.

In view of the results mentioned above and discussion, the ameliorating effect of OTC and/or MSCs on lung tissue might be due to their ability to lower reactive oxygen species and inflammations and then enhance cell cycling and proliferation, besides the powerful skills of MSCs to home and differentiate into tissue cells. However, further studies were needed about the role of MSCs and OTC combination against the chronic CPF-lung toxicity, as the experimental trial was for 30 days only.

\section{Conclusions}

In conclusion, this study has shown a new approach that combines OTC and MSCs therapy to treat lung toxicity induced by CPF in male rats. We found that infusion of OTC and MSCs could significantly regulate hyperlipidemia and some biochemical features, which may be considered as 
risks of acute and chronic pulmonary diseases. Also, OTC and MSCs promote the recovery of lung tissue via increasing cell proliferation confirmed by immune-histochemical evaluation.

\section{Funding}

This work is supported by the Ministry of High Education \& Scientific research, State of Libya, Grant Number: 03, 2018.

\section{Acknowledgments}

The authors thank the Ministry of High Education \& Scientific research, the State of Libya, for supporting this work.

\section{Conflicts of Interest}

\section{The authors declare no conflict of interest.}

\section{References}

1. Rajabzadeh, N.; Fathi, E.; Farahzadi, R. Stem cell-based regenerative medicine. Stem cell investigation 2019, 6, 19, https://doi.org/10.21037/sci.2019.06.04.

2. Karamini, A.; Bakopoulou, A.; Andreadis, D.; Gkiouras, K.; Kritis, A. Therapeutic potential of mesenchymal stromal stem cells in rheumatoid arthritis: a systematic review of in vivo studies. Stem Cell Reviews and Reports 2020, 16, https://doi.org/10.1007/s12015-020-09954-z.

3. Xu, T.; Zhang, Y.; Chang, P.; Gong, S.; Shao, L.; Dong, L. Mesenchymal stem cell-based therapy for radiationinduced lung injury. Stem cell research \& therapy 2018, 9, 18, https://doi.org/10.1186/s13287-018-0776-6.

4. Li, X.; Wang, T.; Liu, J.; Liu, Y.; Zhang, J.; Lin, J.; Zhao, Z.; Chen, D. Effect and mechanism of wedelolactone as antioxidant-coumestan on $\mathrm{OH}$-treated mesenchymal stem cells. Arabian Journal of Chemistry 2020, 13, 184192, https://doi.org/10.1016/j.arabjc.2017.03.008.

5. Zhang, L.; Li, Q.; Liu, W.; Liu, Z.; Shen, H.; Zhao, M. Mesenchymal stem cells alleviate acute lung injury and inflammatory responses induced by paraquat poisoning. Medical science monitor: international medical journal of experimental and clinical research 2019, 25, 2623, https://doi.org/10.12659/msm.915804.

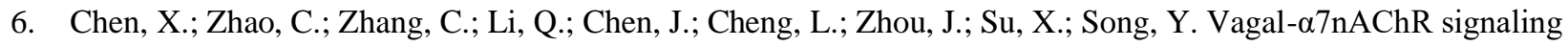
promotes lung stem cells regeneration via fibroblast growth factor 10 during lung injury repair. Stem cell research \& therapy 2020, 11, 1-13, https://doi.org/10.1186/s13287-020-01757-w.

7. Liu, Y.; Min, J.-W.; Feng, S.; Subedi, K.; Qiao, F.; Mammenga, E.; Callegari, E.; Wang, H. Therapeutic role of a cysteine precursor, OTC, in ischemic stroke is mediated by improved proteostasis in mice. Translational stroke research 2020, 11, 147-160, https://doi.org/10.1007/s12975-019-00707-w.

8. Bourgonje, A.R.; von Martels, J.Z.; Bulthuis, M.L.; van Londen, M.; Faber, K.N.; Dijkstra, G.; van Goor, H. Crohn's disease in clinical remission is marked by systemic oxidative stress. Frontiers in physiology 2019, 10, 499, https://doi.org/10.3389/fphys.2019.00499.

9. Gould, R.L.; Pazdro, R. Impact of supplementary amino acids, micronutrients, and overall diet on glutathione homeostasis. Nutrients 2019, 11, 1056, http://doi.org/10.3390/nu11051056.

10. ur Rahman, H.U.; Asghar, W.; Nazir, W.; Sandhu, M.A.; Ahmed, A.; Khalid, N. A comprehensive review on chlorpyrifos toxicity with special reference to endocrine disruption: Evidence of mechanisms, exposures and mitigation strategies. Science of The Total Environment 2021, 755, 142649, https://doi.org/10.1016/j.scitotenv.2020.142649.

11. Zhou, W.; Zhang, C.; Wang, P.; Deng, Y.; Dai, H.; Xi, Q.; Tian, J.; Zhao, M.; Wu, G.; Zhao, L. Low-level Chlorpyrifos Exposure Affects Synaptic Plasticity in Hippocampal Neurons. Research Square 2021, https://doi.org/10.21203/rs.3.rs-377989/v1. 
12. Rauh, V.; Arunajadai, S.; Horton, M.; Perera, F.; Hoepner, L.; Barr, D.B.; Whyatt, R. Seven-year neurodevelopmental scores and prenatal exposure to chlorpyrifos, a common agricultural pesticide. Environmental health perspectives 2011, 119, 1196-1201, https://doi.org/10.1289/ehp.1003160.

13. Naime, A.A.; Lopes, M.W.; Colle, D.; Dafré, A.L.; Suñol, C.; da Rocha, J.B.T.; Aschner, M.; Leal, R.B.; Farina, M. Glutathione in Chlorpyrifos-and Chlorpyrifos-Oxon-Induced Toxicity: a Comparative Study Focused on Noncholinergic Toxicity in HT22 Cells. Neurotoxicity Research 2020, 38, 603-610, https://doi.org/10.1007/S12640020-00254-5.

14. Qiao, D.; Seidler, F.J.; Padilla, S.; Slotkin, T.A. Developmental neurotoxicity of chlorpyrifos: what is the vulnerable period? Environmental health perspectives 2002, 110, 1097-1103, http://doi.org/10.1289/ehp.021101097.

15. Ahmed, M.A.; Ahmed, H.I.; El-Morsy, E.M. Melatonin protects against diazinon-induced neurobehavioral changes in rats. Neurochemical research 2013, 38, 2227-2236, https://doi.org/10.1007/s11064-013-1134-9.

16. Meijer, M.; Brandsema, J.A.; Nieuwenhuis, D.; Wijnolts, F.M.; Dingemans, M.M.; Westerink, R.H. Inhibition of voltage-gated calcium channels after subchronic and repeated exposure of PC12 cells to different classes of insecticides. Toxicological sciences: an official journal of the Society of Toxicology 2015, 147, 607-617, https://doi.org/10.1093/toxsci/kfv154.

17. Chebabo, S.; Santos, M.; Albuquerque, E. The organophosphate sarin, at low concentrations, inhibits the evoked release of GABA in rat hippocampal slices. Neurotoxicology 1999, 20, 871-882.

18. Videira, R.A.; Antunes-Madeira, M.C.; Lopes, V.n.I.; Madeira, V.t.M. Changes induced by malathion, methylparathion and parathion on membrane lipid physicochemical properties correlate with their toxicity. Biochimica et Biophysica Acta (BBA)-Biomembranes 2001, 1511, 360-368, https://doi.org/10.1016/s00052736(01)00295-4.

19. Szafran, B.N.; Borazjani, A.; Seay, C.N.; Carr, R.L.; Lehner, R.; Kaplan, B.L.; Ross, M.K. Effects of Chlorpyrifos on Serine Hydrolase Activities, Lipid Mediators, and Immune Responses in Lungs of Neonatal and Adult Mice. Chemical Research in Toxicology 2021, https://doi.org/10.1021/acs.chemrestox.0c00488.

20. Shaikh, N.I.; Sethi, R. Impairment of apoptosis pathway via Apaf1 downregulation during chlorpyrifos and/or cypermethrin induced lung damage. Animal Biotechnology 2021, 1-8, https://doi.org/10.1080/10495398.2021.1981918.

21. Farkhondeh, T.; Mehrpour, O.; Sadeghi, M.; Aschner, M.; Aramjoo, H.; Roshanravan, B.; Samarghandian, S. A systematic review on the metabolic effects of chlorpyrifos. Reviews on Environmental Health 2021, https://doi.org/10.1515/reveh-2020-0150.

22. Chen, H.; Li, Z.; Dong, L.; Wu, Y.; Shen, H.; Chen, Z. Lipid metabolism in chronic obstructive pulmonary disease. International journal of chronic obstructive pulmonary disease 2019, 14, 1009, https://doi.org/ 10.2147/COPD.S196210.

23. Amin, K.A.; Nagy, M.A. Effect of Carnitine and herbal mixture extract on obesity induced by high fat diet in rats. Diabetology \& metabolic syndrome 2009, 1, 1-14, https://doi.org/10.1186/1758-5996-1-17.

24. Joshi, S.C.; Mathur, R.; Gulati, N. Testicular toxicity of chlorpyrifos (an organophosphate pesticide) in albino rat. Toxicology and Industrial Health 2007, 23, 439-444, https://doi.org/10.1177/0748233707080908.

25. Seo, M.-S.; Jeong, Y.-H.; Park, J.-R.; Park, S.-B.; Rho, K.-H.; Kim, H.-S.; Yu, K.-R.; Lee, S.-H.; Jung, J.-W.; Lee, Y.-S. Isolation and characterization of canine umbilical cord blood-derived mesenchymal stem cells. Journal of veterinary science 2009, 10, 181-187, https://doi.org/10.4142/jvs.2009.10.3.181.

26. Danišovič, L.u.; Varga, I.; Zamborský, R.; Böhmer, D. The tissue engineering of articular cartilage: cells, scaffolds and stimulating factors. Experimental biology and medicine 2012, 237, 10-17, https://doi.org/10.1258/ebm.2011.011229.

27. Haasters, F.; Prall, W.C.; Anz, D.; Bourquin, C.; Pautke, C.; Endres, S.; Mutschler, W.; Docheva, D.; Schieker, M. Morphological and immunocytochemical characteristics indicate the yield of early progenitors and represent a quality control for human mesenchymal stem cell culturing. Journal of anatomy 2009, 214, 759-767, http://doi.org/10.1111/j.1469-7580.2009.01065.x.

28. Al Moutaery, M.; Al Rayes, H.; Al Swailam, R.; Elfaki, I.; Khan, H.A.; Arshaduddin, M.; Tariq, M. Protective effect of a cysteine prodrug and antioxidant, L-2-oxothiazolidine-4-carboxylate, against ethanol-induced gastric 
https://doi.org/10.33263/BRIAC126.77527774

lesions in rats. Experimental and toxicologic pathology 2012, 64, 233-237, https://doi.org/10.1016/j.etp.2010.08.012

29. Raisi Dehkourdi, B.; Fatahian, S.; Shahanipoor, K. Synthesis, characterization and renal toxicity of ZnO and polyethylene glycol coated $\mathrm{ZnO}$ nanoparticles. Nanomedicine Journal 2017, 4, 55-60, https://doi.org/10.22038/NMJ.2017.8054.

30. Kholif, A.; Khattab, H.; El-Shewy, A.; Salem, A.; Kholif, A.; El-Sayed, M.; Gado, H.; Mariezcurrena, M. Nutrient digestibility, ruminal fermentation activities, serum parameters and milk production and composition of lactating goats fed diets containing rice straw treated with Pleurotus ostreatus. Asian-Australasian Journal of Animal Sciences 2014, 27, 357, https://doi.org/10.5713/ajas.2013.13405.

31. Daumas, B.; Watson, W.; Biggs, H. Albumin Standards and Measurements of Serum-Albumin. Clin. Che. Acta 1971, 31, 81-82, https://doi.org/10.1016/0009-8981(71)90365-2.

32. Siedel, J.; Hägele, E.; Ziegenhorn, J.; Wahlefeld, A.W. Reagent for the enzymatic determination of serum total cholesterol with improved lipolytic efficiency. Clinical chemistry 1983, 29, 1075-1080, https://doi.org/10.1093/clinchem/29.6.1075.

33. Fossati, P.; Prencipe, L. Serum triglycerides determined colorimetrically with an enzyme that produces hydrogen peroxide. Clinical chemistry 1982, 28, 2077-2080, https://doi.org/10.1093/CLINCHEM/28.10.2077.

34. Assmann, G.; Jabs, H.-U.; Kohnert, U.; Nolte, W.; Schriewer, H. LDL-cholesterol determination in blood serum following precipitation of LDL with polyvinylsulfate. Clinica Chimica Acta 1984, 140, 77-83, https://doi.org/10.1016/0009-8981(84)90153-0.

35. Okura, Y.; Takeda, K.; Honda, S.; Hanawa, H.; Watanabe, H.; Kodama, M.; Izumi, T.; Aizawa, Y.; Seki, S.; Abo, T. Recombinant murine interleukin-12 facilitates induction of cardiac myosin-specific type 1 helper $\mathrm{T}$ cells in rats. Circulation research 1998, 82, 1035-1042, https://doi.org/10.1161/01.res.82.10.1035.

36. Bajwa, E.K.; Khan, U.A.; Januzzi, J.L.; Gong, M.N.; Thompson, B.T.; Christiani, D.C. Plasma C-reactive protein levels are associated with improved outcome in ARDS. Chest 2009, 136, 471-480, https://doi.org/10.1378/chest.08-2413.

37. Amorim, M.R.; Bonagamba, L.G.; Souza, G.M.; Moraes, D.J.; Machado, B.H. Role of respiratory changes in the modulation of arterial pressure in rats submitted to sino-aortic denervation. Experimental physiology 2016, 101, 1359-1370, https://doi.org/10.1113/EP085897.

38. He, X.; Ii, K.; Muguruma, N.; Hayashi, S.; Ito, S. Expression of Proliferating Cell Nuclear Antigen (PCNA) in biopsy and autopsy specimens of gastric carcinoma. Journal of Medical Investigation 1998, 44, 149-154.

39. Shaikh, N.I.; Sethi, R. Exposure to chlorpyrifos and cypermethrin alone or in combination induces developmental abnormalities and lung damage in animal models: A review. Journal of Entomology and Zoology Studies 2020, 8, 1923-1928, https://doi.org/10.22271/j.ento.2020.v8.i5aa.7769.

40. Sethi, R.S.; Schneberger, D.; Charavaryamath, C.; Singh, B. Pulmonary innate inflammatory responses to agricultural occupational contaminants. Cell and tissue research 2017, 367, 627-642, https://doi.org/10.1007/s00441-017-2573-4.

41. Owumi, S.E.; Dim, U.J. Manganese suppresses oxidative stress, inflammation and caspase-3 activation in rats exposed to chlorpyrifos. Toxicology Reports 2019, 6, 202-209, https://doi.org/10.1016/j.toxrep.2019.02.007.

42. Deb, N.; Das, S. Chlorpyrifos toxicity in fish: a review. Current World Environment 2013, 8, 77, http://dx.doi.org/10.12944/CWE.8.1.17.

43. Wang, B.; Tsakiridis, E.E.; Zhang, S.; Llanos, A.; Desjardins, E.M.; Yabut, J.M.; Green, A.E.; Day, E.A.; Smith, B.K.; Lally, J.S. The pesticide chlorpyrifos promotes obesity by inhibiting diet-induced thermogenesis in brown adipose tissue. Nature communications 2021, 12, 1-12, https://doi.org/10.1038/s41467-021-25384-y.

44. Ravikumar, Y.; Madhuri, D.; Lakshman, M.; Reddy, A.G.; Kalakumar, B. Haematological Alterations Induced by Cadmium (Cd) and Chlorpyrifos (CPF) in Male Wistar albino Rats. Int. J. Curr. Microbiol. App. Sci 2019, 8, 480-485, https://doi.org/10.20546/ijcmas.2019.808.055.

45. Al-Baggou, B.K. Subacute cholinesterase inhibition and behavioral effects of chlorpyrifos experimentally supplied via drinking water in chicks. Human and Veterinary Medicine 2018, 6, 70-75.

46. Zhang, P.; Liu, L.; Yao, L.; Song, X. Improved Differentiation Ability and Therapeutic Effect of miR-23a-3p Expressing Bone Marrow-Derived Mesenchymal Stem Cells in Mice Model with Acute Lung Injury. Int J Stem Cells 2021, 14, 229-239, https://doi.org/10.15283/ijsc20136. 
47. Cardenes, N.; Aranda-Valderrama, P.; Carney, J.P.; Sellares Torres, J.; Alvarez, D.; Kocyildirim, E.; Wolfram Smith, J.A.; Ting, A.E.; Lagazzi, L.; Yu, Z. Cell therapy for ARDS: efficacy of endobronchial versus intravenous administration and biodistribution of MAPCs in a large animal model. BMJ Open Respiratory Research 2019, 6, e000308, https://doi.org/10.1136/bmjresp-2018-000308.

48. Li, L.; Dong, L.; Wang, Y.; Zhang, X.; Yan, J. Lats1/2-Mediated Alteration of Hippo Signaling Pathway Regulates the Fate of Bone Marrow-Derived Mesenchymal Stem Cells. BioMed research international 2018, 2018, 4387932, https://doi.org/10.1155/2018/4387932.

49. Mansour, S.A.; Mossa, A.-T.H. Oxidative damage, biochemical and histopathological alterations in rats exposed to chlorpyrifos and the antioxidant role of zinc. Pesticide Biochemistry and Physiology 2010, 96, 14-23, https://doi.org/10.1016/j.pestbp.2009.08.008.

50. Bauman, P.F.; Smith, T.K.; Bray, T.M. Effect of Dietary Protein Deficiency and L-2-Oxothiazolidine-4Carboxylate on the Diurnal Rhythm of Hepatic Glutathione in the Rat. The Journal of Nutrition 1988, 118, 10481054, https://doi.org/10.1093/jn/118.8.1048.

51. Levy, M.A.; Sikorski, B.; Bray, T.M. Selective Elevation of Glutathione Levels in Target Tissues with L-2Oxothiazolidine-4-Carboxylate (OTC) Protects against Hyperoxia-Induced Lung Damage in Protein-Energy Malnourished Rats: Implications for a New Treatment Strategy. The Journal of Nutrition 1998, 128, 671-676, https://doi.org/10.1093/jn/128.4.671.

52. Kotton, D.N.; Morrisey, E.E. Lung regeneration: mechanisms, applications and emerging stem cell populations. Nat Med 2014, 20, 822-832, https://doi.org/10.1038/nm.3642.

53. Tsolaki, E.; Yannaki, E. Stem cell-based regenerative opportunities for the liver: State of the art and beyond. World J Gastroenterol 2015, 21, 12334-12350, https://doi.org/10.3748/wjg.v21.i43.12334.

54. Sehlmeyer, K.; Ruwisch, J.; Roldan, N.; Lopez-Rodriguez, E. Alveolar Dynamics and Beyond - The Importance of Surfactant Protein C and Cholesterol in Lung Homeostasis and Fibrosis. Frontiers in physiology 2020, 11, 386386, https://doi.org/10.3389/fphys.2020.00386.

55. Mongi, S.; Riadh, B.; Noura, B.; Fatma, R.; Kamel, J.; Abdelfattah, E.F. Antioxidant and protective effects of Artemisia campestris essential oil against chlorpyrifos-induced kidney and liver injuries in rats. Frontiers in Physiology 2021, 12, 194, https://doi.org/10.3389/fphys.2021.618582.

56. Guibourdenche, M.; El Khayat El Sabbouri, H.; Bonnet, F.; Djekkoun, N.; Khorsi-Cauet, H.; Corona, A.; Guibourdenche, J.; Bach, V.; Anton, P.M.; Gay-Quéheillard, J. Perinatal exposure to chlorpyrifos and/or a highfat diet is associated with liver damage in male rat offspring. Cells \& Development 2021, 166, 203678, https://doi.org/10.1016/j.cdev.2021.203678.

57. Xue, B.; Xiao, X.; Yu, T.; Xiao, X.; Xie, J.; Ji, Q.; Wang, L.; Na, T.; Meng, S.; Qian, L. Mesenchymal stem cells modified by FGF21 and GLP1 ameliorate lipid metabolism while reducing blood glucose in type 2 diabetic mice. Stem Cell Research \& Therapy 2021, 12, 1-15, https://doi.org/10.1186/s13287-021-02205-z.

58. De Anna, J.S.; Castro, J.M.; Darraz, L.A.; Elías, F.D.; Cárcamo, J.G.; Luquet, C.M. Exposure to hydrocarbons and chlorpyrifos alters the expression of nuclear receptors and antioxidant, detoxifying, and immune response proteins in the liver of the rainbow trout, Oncorhynchus mykiss. Ecotoxicology and Environmental Safety 2021, 208, 111394, https://doi.org/ 10.1016/j.ecoenv.2020.111394.

59. Yang, J.; Gong, Y.; Cai, J.; Zheng, Y.; Liu, H.; Zhang, Z. Chlorpyrifos induces redox imbalance-dependent inflammation in common carp lymphocyte through dysfunction of T-cell receptor $\gamma$. Journal of fish diseases 2020, 43, 423-430, https://doi.org/ 10.1111/jfd.13138.

60. Chen, D.; Zhang, Z.; Yao, H.; Cao, Y.; Xing, H.; Xu, S. Pro-and anti-inflammatory cytokine expression in immune organs of the common carp exposed to atrazine and chlorpyrifos. Pesticide biochemistry and physiology 2014, 114, 8-15, https://doi.org/10.1016/j.pestbp.2014.07.011.

61. Promsote, W.; Rajalakshmi Veeranan-Karmegam, S.A.; Shen, D.; Chan, C.-C.; Lambert, N.A.; Ganapathy, V.; Martin, P.M. L-2-oxothiazolidine-4-carboxylic acid attenuates oxidative stress and inflammation in retinal pigment epithelium. Molecular vision 2014, 20, 73.

62. Jacques, C.; Bacqueville, D.; Jeanjean-Miquel, C.; Génies, C.; Noizet, M.; Tourette, A.; Bessou-Touya, S.; Duplan, H. Sustained effect of two antioxidants (oxothiazolidine and $\delta$-tocopheryl glucoside) for immediate and long-term sun protection in a sunscreen emulsion based on their different penetrating properties. International Journal of Cosmetic Science 2021, https://doi.org/10.1111/ics.12705. 
63. Markov, A.; Thangavelu, L.; Aravindhan, S.; Zekiy, A.O.; Jarahian, M.; Chartrand, M.S.; Pathak, Y.; Marofi, F.; Shamlou, S.; Hassanzadeh, A. Mesenchymal stem/stromal cells as a valuable source for the treatment of immunemediated disorders. Stem cell research \& therapy 2021, 12, 1-30, https://doi.org/10.1186/s13287-021-02265-1.

64. Lou, S.; Duan, Y.; Nie, H.; Cui, X.; Du, J.; Yao, Y. Mesenchymal stem cells: Biological characteristics and application in disease therapy. Biochimie 2021, https://doi.org/10.1016/j.biochi.2021.03.003.

65. Fang, S.-B.; Zhang, H.-Y.; Meng, X.-C.; Wang, C.; He, B.-X.; Peng, Y.-Q.; Xu, Z.-B.; Fan, X.-L.; Wu, Z.-J.; Wu, Z.-C. Small extracellular vesicles derived from human MSCs prevent allergic airway inflammation via immunomodulation on pulmonary macrophages. Cell death \& disease 2020, 11, 1-15, https://doi.org/10.1038/s41419-020-2606-X.

66. Casati, S.; Giannasi, C.; Niada, S.; Bergamaschi, R.F.; Orioli, M.; Brini, A.T. Bioactive Lipids in MSCs Biology: State of the Art and Role in Inflammation. International Journal of Molecular Sciences 2021, 22, 1481, https://doi.org/10.3390/ijms22031481.

67. Neder, J.A.; Berton, D.C.; O’Donnell, D.E. Arterial blood gases in the differential diagnosis of hypoxemia. Journal Brasileiro de Pneumologia 2020, 46, https://doi.org/10.36416/1806-3756/e20200505.

68. Shaikh, N.I.; Sethi, R. Differential gene expression profile of mice lung following chronic dietary exposure to chlorpyrifos and/or cypermethrin. Journal of Entomology and Zoology Studies 2021, https://doi.org/10.22271/j.ento.2021.v9.i1b.8139.

69. Yurumez, Y.; Ikizceli, I.; Sozuer, E.M.; Soyuer, I.; Yavuz, Y.; Avsarogullari, L.; Durukan, P. Effect of interleukin-10 on tissue damage caused by organophosphate poisoning. Basic \& clinical pharmacology \& toxicology 2007, 100, 323-327, http://doi.org/10.1111/j.1742-7843.2007.00049.x.

70. El-Kerdasy, H.I.; Elsayed, A.M.; Mousa, H.R. Ameliorative Effect of Ginger Extract and Selenium in theThyroid Gland Toxicity Induced by Chlorpyrifos in Male Albino Rats. The Egyptian Journal of Hospital Medicine 2021, 83, 824-830, https://doi.org/10.21608/EJHM.2021.156452.

71. Kassab, A.A.; El-Aasr, M. Effect of Avocado pulp extract on chlorpyrifos-induced thyroid gland injury in rats: A histological and morphometric study. Egyptian Journal of Histology 2018, 41, 83-92, https://doi.org/10.21608/EJH.2018.7524.

72. Niture, S.K.; Velu, C.S.; Smith, Q.R.; Bhat, G.J.; Srivenugopal, K.S. Increased expression of the MGMT repair protein mediated by cysteine prodrugs and chemopreventative natural products in human lymphocytes and tumor cell lines. Carcinogenesis 2007, 28, 378-389, http://doi.org/10.1093/carcin/bgl155.

73. Sabry, M.M.; Elkalawy, S.A.-E.; Abo-Elnour, R.K.E.-d.; Abd-El-Maksod, D.F. Histolgical and immunohistochemical study on the effect of stem cell therapy on bleomycin induced pulmonary fibrosis in albino rat. Int J Stem Cells 2014, 7, 33, https://doi.org/10.15283/ijsc.2014.7.1.33.

74. Condeelis, J.; Segall, J.E. Intravital imaging of cell movement in tumours. Nature Reviews Cancer 2003, 3, 921930, https://doi.org/10.1038/nrc1231.

75. Kalluri, R.; Neilson, E.G. Epithelial-mesenchymal transition and its implications for fibrosis. The Journal of clinical investigation 2003, 112, 1776-1784, https://doi.org/10.1172/JCI20530. 